\title{
The effect of testicular irradiation on Leydig cell function in prepubertal boys with acute lymphoblastic leukaemia
}

\author{
A D LEIPER, D B GRANT, AND J M CHESSELLS \\ Departments of Haematology/Oncology and Endocrinology, The Hospital for Sick Children and \\ Institute of Child Health, Great Ormond Street, London
}

SUMMARY Testicular function was investigated by the luteinising hormone releasing hormone (LHRH) test and a three day human chorionic gonadotrophin (HCG) test in 11 prepubertal boys with acute lymphoblastic leukaemia (ALL) who had received 2400 rads of fractionated radiation to their testes after relapse at this site. The results were compared with an unirradiated control group. Basal and peak testosterone values after 1000 units of HCG were significantly lower in the irradiated patients than in the control group. Peak follicle stimulating hormone (FSH) values after $100 \mu \mathrm{g}$ LHRH were significantly higher in irradiated boys, but there was no difference in either basal FSH or basal and peak luteinising hormone values. The findings suggest that the ability of the Leydig cell to produce testosterone-as detected by the HCG test-is appreciably reduced after irradiation and that tubular dysfunction in prepubertal boys may sometimes be predicted by a raised FSH response.

This study was prompted by the increasing incidence of testicular relapse in acute lymphoblastic leukaemia (ALL). This is a reflection of the improved prognosis of childhood leukaemia, with longer first remissions and a greater proportion of children completing treatment. Thirteen percent of boys terminate their first remissions with a testicular relapse, usually within one year of stopping chemotherapy.1

In June 1977 the Medical Research Council Working Party on Childhood Leukaemia recommended that routine testicular biopsies should be performed on all male patients to detect subclinical infiltration. This has now been implemented and takes place two years from the start of treatment, at the time of randomisation to a further year of treatment. Biopsies were also performed on all boys who had completed treatment within the previous two years. It was also suggested at this time that prophylactic testicular irradiation should be employed in the hope of reducing this complication. This proposal met with considerable resistance from both doctors and patients, however, largely because the effect of irradiation on future Leydig cell function was unknown.

The purpose of this study was to investigate testicular function 6 months after 2400 rads of irradiation, with particular reference to testosterone secretion after human chorionic gonadotrophin (HCG) stimulation.

\section{Patients and methods}

Patients. Eleven prepubertal boys with ALL who had suffered testicular relapses were tested using the luteinising hormone releasing hormone (LHRH) and three day HCG tests 6 months after irradiation. Six of these children had presented clinically with testicular swellings, and five were found to have infiltrated routine biopsies. Of 7 boys who had bilateral involvement, four had dense infiltrates. The other four patients were affected unilaterally.

Irradiation consisted of 2400 rads to both testes in 10 or 12 fractions over 14-16 days. Patients also underwent a re-induction and consolidation course of chemotherapy lasting 10 weeks, and including vincristine $\left(1.5 \mathrm{mg} / \mathrm{m}^{2} /\right.$ dose $)$, prednisolone $(40$ $\mathrm{mg} / \mathrm{m}^{2} /$ dose $)$, cytosine arabinoside $\left(100 \mathrm{mg} / \mathrm{m}^{2} /\right.$ dose $)$, and cyclophosphamide $\left(600 \mathrm{mg} / \mathrm{m}^{2} /\right.$ dose $)-2$ doses only-and asparaginase (10 000 units $/ \mathrm{m}^{2} /$ dose $)$. In addition, five intrathecal injections of methotrexate were given. Eleven control patients with ALL were chosen from boys who had negative routine biopsies. 
Table Data on age, bone age, protocol, and presence of continuing treatment in patients and controls

\begin{tabular}{lllll}
\hline Case No & $\begin{array}{l}\text { Chronological } \\
\text { age } \\
\text { (years) }\end{array}$ & $\begin{array}{l}\text { Bone age } \\
\text { (years) }\end{array}$ & $\begin{array}{l}\text { Treatment } \\
\text { protocol* }\end{array}$ & $\begin{array}{l}\text { Continuing } \\
\text { treatment }\end{array}$ \\
\hline
\end{tabular}

\begin{tabular}{crrlll}
\hline $\begin{array}{l}\text { Patients } \\
(\mathrm{n}=11)\end{array}$ & & & & \\
1 & 8.37 & 9.5 & V & + \\
2 & 8.78 & $8 \cdot 1$ & V & + \\
3 & 4.35 & 4.7 & IV & + \\
4 & 4.45 & 5.3 & V & + \\
5 & 9.18 & 7.5 & V & + \\
6 & 7.58 & 7.9 & II & + \\
7 & 8.04 & $8 \cdot 1$ & GOS & + \\
8 & 8.00 & 7.8 & GOS + III & + \\
9 & 9.16 & 10.1 & V & + \\
10 & 9.21 & 9.0 & GOS & + \\
11 & 8.16 & 7.8 & V & + \\
& & & & & +
\end{tabular}

Controls

$\begin{array}{rrrll}\text { (n=11) } & & & & \\ 1 & 10.53 & 9.4 & \text { V } & - \\ 2 & 7.86 & 7.8 & \text { III } & - \\ 3 & 5.06 & 4.7 & \text { V } & + \\ 4 & 6.67 & 5.2 & \text { V } & + \\ 5 & 7.27 & 7.8 & \text { V } & + \\ 6 & 6.32 & 7.8 & \text { III } & - \\ 7 & 8.00 & 7.9 & \text { III } & - \\ 8 & 5.53 & 7.8 & \text { IV } & + \\ 9 & 10.50 & 9.9 & \text { V } & + \\ 10 & 10.36 & 9.3 & \text { GOS } & - \\ 11 & 9.10 & 7.5 & \text { V } & -\end{array}$

*UKALL protocols are designed by the Medical Research Council Working Party on Childhood Leukaemia.

UKALL II-V and the Great Ormond Street Hospital regimes (GOS) contain vincristine, prednisolone, asparaginase, 6-mercaptopurine, and methotrexate.

UKALL II and III contain additional drugs including cyclophosphamide, cytosine arabinoside, and adriamycin.

All were prepubertal (Tanner, stage I) ${ }^{2}$ and were bone age matched with the patient group (Table). They were tested 6 months after the biopsy. Bone age was chosen to match patients and controls in an attempt to produce uniformity in this study and in the proposed follow up, when many of these children will be pubertal. Skeletal age correlates better with testosterone secretion as puberty approaches than does chronological age.

All patients and controls had undergone cranial prophylaxis and had been treated for 2-3 years with conventional chemotherapy (Table). Six control patients had finished treatment when the tests were performed, while the other five, and all those in the patient group, were still receiving treatment. None of the boys had received more than $365 \mathrm{mg} / \mathrm{kg}$ of cyclophosphamide - found to be the critical cumulative dose for tubular damage ${ }^{3}$ - but it was impossible to exclude those treated with cytosine arabinoside, which is known to impair tubular morphology but not Leydig cell function in total doses of greater than $1 \mathrm{gm} / \mathrm{m}^{2}{ }^{45}$

Method. Bone age was assessed using the Tanner and Whitehouse method. ${ }^{6}$ Patients and controls were matched to within 0.3 years.

LHRH and three day HCG tests were performed on an outpatient basis. Blood samples $(2-4 \mathrm{ml})$ were drawn for estimation of basal serum luteinising hormone ( $\mathrm{LH})$, follicle stimulating hormone (FSH), and plasma testosterone. LHRH $(100 \mu \mathrm{g})$ was injected intravenously and further samples for $\mathrm{LH}$ and FSH were taken 20 and 60 minutes later. One hour later 1000 units HCG (Pregnyl) were given by IM injection and two further doses were given on the next two days, 24 hours apart. Venous blood $(2 \mathrm{ml})$ was drawn for measurement of plasma testosterone 24 hours after the third HCG injection. LH and FSH values were estimated by double antibody immunoassay.

Plasma testosterone was estimated by radioimmunoassay using antiserum raised against testosterone-3-oxine bovine serum albumin conjugate. This antiserum shows $76 \%$ cross reactivity with 5 - $\alpha$-dihydrotestosterone but negligible cross reactivity with other androgens.?

All assays were performed in duplicate-the

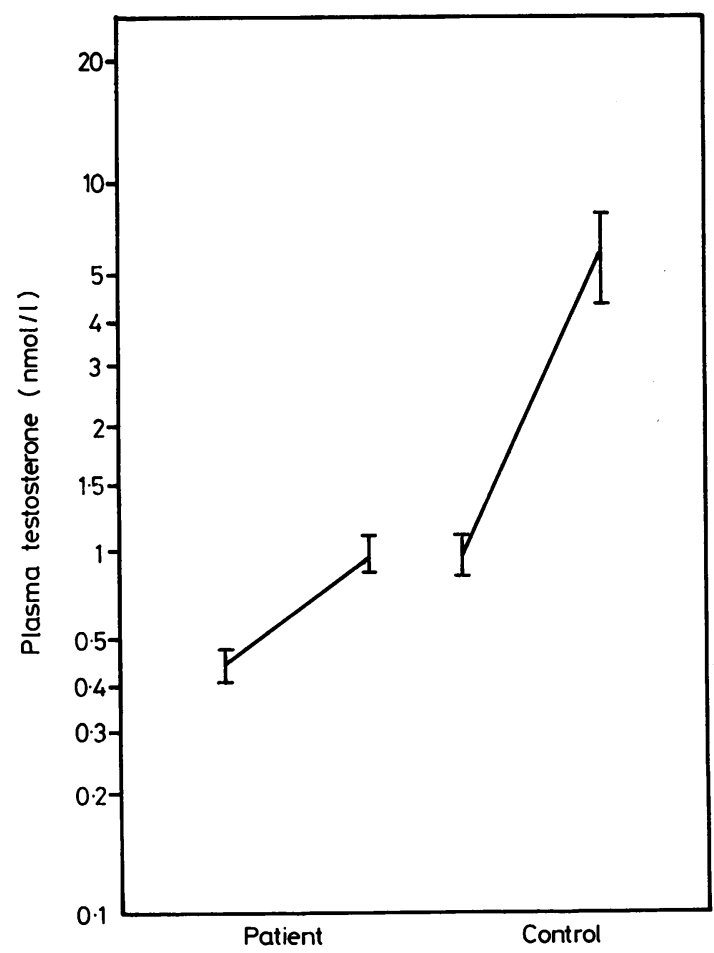

Fig. 1 Plasma testosterone values, mean (SEM), before and after human chorionic gonadotrophin stimulation in 11 leukaemic boys with previous testicular irradiation and 11 unirradiated controls. 
interassay variation being $11 \%$ for $\mathrm{LH}$ and $\mathrm{FSH}$ and $10.4 \%$ for testosterone.

Statistical methods. All peak and basal values were compared with those of the controls using the Mann-Whitney U test.

\section{Results}

Testosterone. Fig. 1 shows basal and peak values of testosterone after HCG stimulation in irradiated boys compared with controls, expressed as mean values and their standard errors. Basal and peak values were both significantly lower in the irradiated group $(\mathrm{P}<0.01$ and $\mathbf{P}<0.01$, respectively).

The 11 boys in the patient group showed increments in plasma testosterone between 0 and 0.8 $\mathrm{nmol} / \mathrm{l}$, with a mean basal value of $0.45 \mathrm{nmol} / \mathrm{l}$ (range $0.3-1.7 \mathrm{nmol} / \mathrm{l}$ ). In the control group the increments were between 0.9 and $15.1 \mathrm{nmol} / 1$, with mean basal and peak values respectively of 0.98 $\mathrm{nmol} / \mathrm{l}$ (range 0.4-1.9 nmol/l) and 5.76 nmol/1 (range $1 \cdot 5-17 \mathrm{nmol} / \mathrm{l}$ ). Absolute peak values were below $2 \mathrm{nmol} / 1$ in all 11 irradiated boys but in only one control.

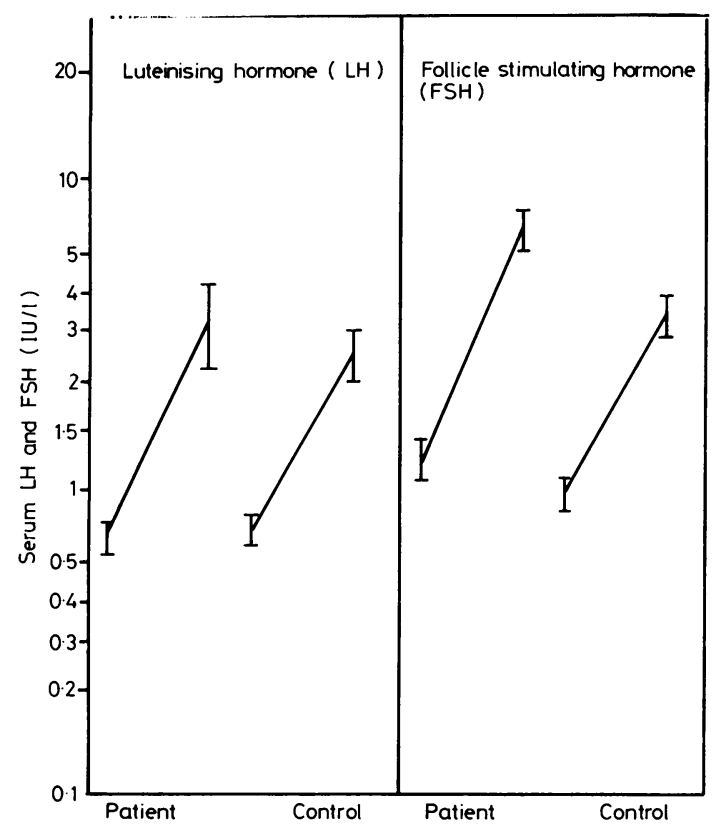

Fig. 2 Serum luteinising hormone and follicle stimulating hormone, mean (SEM), after luteinising hormone releasing hormone $(100 \mu \mathrm{g})$ stimulation in 11 leukaemic boys with previous testicular irradiation and 11 unirradiated controls.
LH and FSH responses. $\mathrm{LH}$ and FSH responses to LHRH of patients and controls are compared in Fig. 2. There was no statistically significant difference in either basal or peak LH values.

Three patients and two controls showed no rise in LH after LHRH stimulation. One patient in the irradiated group had a very high $\mathrm{LH}$ value $(11 \cdot 7$ IU/l) for his age, although this had been normal before irradiation when he was tested for other reasons.

There was no significant difference in basal values of FSH. Peak FSH values were significantly higher in irradiated patients $(\mathrm{P}<0.05)$ but in only four did these rise above values considered, by other authors, to represent the possible upper limit of normal. The mean peak value for the patient group was $6 \cdot 10 \mathrm{IU} / 1$ (range $1 \cdot 8-15 \cdot 2 \mathrm{IU} / \mathrm{l})$ and for the control group 3.39 IU/1 (range 1.6-6.0 IU/1).

\section{Discussion}

Interpretation of results has been difficult because of the lack of absolute values in prepubertal children, interlaboratory variation, and variability of hormone values within the same individual. Gonadotrophin values of our control patients compare favourably with those of several other authors, ${ }^{8-11}$ apart from higher peak FSH values in our series. Basal and peak testosterone after HCG in the same controls compare well with those of Shalet et al., ${ }^{5}$ Rudd et al.,$^{12}$ and Cacciari et al. ${ }^{13}$

Our results strongly suggest that 2400 rads of fractionated testicular irradiation can depress Leydig cell function. This is shown by the significant difference $(\mathrm{P}<0.01)$ in peak testosterone values in irradiated patients and controls. When considering this conclusion, however, it must be born in mind that the patient and control groups were not strictly comparable in terms of treatment protocols (Table), nor was it possible to match the two groups for duration of chemotherapy. Although all the patients who had testicular relapses were receiving treatment and had had a second induction course of chemotherapy, only 6 controls were still receiving treatment at the time of the tests. We were unable to exclude this variable because of the predetermined timing of biopsies at patient randomisation.

The significant reduction in basal values of testosterone in the irradiated group is surprising $(\mathrm{P}<0.01)$ as it is known that even anorchic patients can have basal values up to $1.9 \mathrm{nmol} / 1^{7}$ as a result of testosterone secretion by the adrenal glands. ${ }^{14}$ It is possible that this difference, and indeed the differences in the peak testosterone responses 6 months after radiotherapy, might be caused by a reduction in sex hormone binding globulin (SHBG) 
as a result of the additional chemotherapy received by our irradiated patients. It is known that induction chemotherapy consisting of vincristine, prednisolone, daunorubicin, and asparaginase causes a fall in SHBG, presumably by inhibition of hepatic synthesis. ${ }^{15}$ It is also known that this effect lasts only up to four weeks, until the beginning of consolidation and maintenance therapy. The SHBG then begins to rise and reaches normal values shortly afterwards. ${ }^{15}$ It is therefore highly unlikely that SHBG values would still be low 6 months later, at the time when our tests would have been performed.

The results of Shalet et al. tend to corroborate our impression that changes in testosterone values were caused by radiotherapy alone and not by chemotherapy. Although they found profound morphological changes in the tubular portion of testes from pubertal and prepubertal patients alike in individuals treated with standard chemotherapy for ALL, ${ }^{4}$ they found no difference in androgen response to HCG in their treated groups. ${ }^{5}$ They were unable to detect tubular damage in prepubertal patients by the LHRH test. ${ }^{5}$ Another possibility that might account for the reduced responsiveness of the testes to HCG after radiotherapy is leukaemic infiltration per se. We felt that this was unlikely because, of the 7 boys who had bilateral infiltration, in only four was this heavy, and in the remaining four boys infiltration was unilateral. It seems a valid assumption therefore that our results reflect irradiation damage.

Interestingly, although only four values fell outside the normal range, we found a significant difference in peak FSH values between the irradiated and control groups despite the prepubertal status of these boys. This may reflect greater damage by irradiation over and above that caused by chemotherapy. It has been suggested that inhibin, produced by the germinal cells of the testis, which in adults restrains FSH secretion by a negative feedback mechanism, plays only a minor role in the prepubertal boy. Instead it seems that the small amount of androgen produced by the Leydig cell may be the active component in controlling gonadotrophin secretion..$^{5}$ Once the restraining influence is removed by loss of Leydig cells, the gonadotrophin values will tend to rise. Increased secretion may only be detected by peak responses to the LHRH test in childhood. There is evidence that FSH values are suppressed more by the negative feedback effects of gonadal steroids than $\mathrm{LH}$ secretion and release $\mathrm{e}^{16}$ which may explain the absence of significant $\mathrm{LH}$ changes in our series.

It is difficult to make recommendations for the future on the basis of this study alone. Our findings that irradiation severely damages the Leydig cell seem to make prophylactic irradiation undesirable. What is not clear, however, is whether there is a capacity for recovery. Certainly Leydig cells show more radioresistance than spermatogonia, ${ }^{11} 1718$ which are known to have some regeneration potential over a period of time..$^{41920}$ It is also true to say that biochemical changes do not necessarily mean that Leydig cell function is so impaired as to prevent transition through puberty. Follow up assessment of these children will be important and such a study is already under way.

\section{References}

1 Report on behalf of the MRC Working Party on Leukaemia in Childhood: Testicular disease in acute lymphoblastic leukaemia in childhood. $\mathrm{Br} \mathrm{Med} J 1978$;i: 334-8.

2 Tanner JM. Growth at adolescence, 2nd edition. Oxford: Blackwell Scientific Publications, 1973:32.

3 Lentz RD, Bergstein J, Steffes MW, et al. Postpubertal evaluation of gonadal function following cyclophosphamide therapy before and during puberty. $J$ Pediatr $1977 ; 91$ :385-94.

4 Lendon M, Hann IM, Palmer MK, Shalet SM, Morris Jones PH. Testicular histology after combination chemotherapy in childhood for acute lymphoblastic leukaemia. Lancet 1978 ;ii:439-41.

5 Shalet SM, Hann IM, Lendon M, Morris Jones PH, Beardwell C. Testicular function after combination chemotherapy in childhood for acute lymphoblastic leukaemia. Arch Dis Child 1981 ;56:275-8.

6 Tanner JM, Whitehouse RH, Marshall WA, Healey MJR, Goldstein H. Assessment of skeletal maturity and prediction of adult height (TW2 method) London: Academic Press, 1975:1-20.

7 Grant DB, Laurance BM, Atherden SM, Ryness J. HCG stimulation test in children with abnormal sexual development. Arch Dis Child 1976;51 :596-601.

8 Job JC, Garnier PE, Chaussain JL, Milhaud G. Elevation of serum gonadotrophins (LH and FSH) after releasing hormone (LH-RH) injection in normal children and in patients with disorders of puberty. $J$ Clin Endocrinol Metab 1972;35:473-6.

9 Dickerman Z, Prager-Lewin R, Laron Z. Response of plasma LH and FSH to synthetic LHRH in children at various pubertal stages. AmJ Dis Child 1976;130:634-8.

10 Gendrel D, Roger M, Chaussain JL, Canlorbe P, Job JC. Correlation of pituitary and testicular responses to stimulation tests in cryptorchid children. Acta Endocrinol (Copenh) 1977;86:641-50.

11 Shalet SM, Beardwell CG, Jacobs HS, Pearson D. Testicular function following irradiation of the human prepubertal testis. Clin Endocrinol $(O x f) 1978 ; 9: 483-90$.

12 Rudd BT, Rayner PHW, Smith MR, Holder G, Jivani SKM, Theodorides CG. Effect of human chorionic gonadotrophin on plasma and urine testosterone in boys with delayed puberty. Arch Dis Child 1973;48:590-95.

13 Cacciari E, Cicognani A, Tassoni P, et al. Plasma testosterone and estradiol concentration in prepubertal boys with cryptorchidism before and after dexamethasone and after human chorionic gonadotropin administration. Helv Paediatr Acta 1974;29:27-34.

14 Zachmann M. The evaluation of testicular endocrine function before and in puberty. Acta Endocrinol [Suppl] (Copenh) 1972;164:20-1,8. 
15 Beck W, Schwarz S, Heidemann PH, Jentsch E, Stubbe P, König A. Hypergonadotropic hypogonadism, SHBG deficiency and hyperprolactinaemia: a transient phenomenon during induction chemotherapy in leukaemic children. Eur J Pediatr 1982;138:216-20.

16 Job JC, Chaussain JL, Garnier PE. The use of luteinizing hormone-releasing hormone in pediatric patients. Horm Res 1977;8:171-87.

17 Rowley MJ, Leach DR, Warner GA, Heller CG. Effect of graded doses of ionizing radiation on the human testis. Radiat Res 1974;59:665-78.

18 Bain J, Keene J. Further evidence for inhibin: change in serum luteinizing hormone and follicle-stimulating hormone levels after $\mathrm{x}$-irradiation of rat testes. $J$ Endocrinol $1975 ; 66: 279-80$.

19 Speiser B, Rubin P, Casarett G. Aspermia following lower truncal irradiation in Hodgkin's disease. Cancer $1973 ; 32: 692-8$.

20 Clubb B, Carter J. Effects of testicular radiation. Australas Radiol 1976;20:64-8.

Correspondence to Dr A D Leiper, Department of Haematology/Oncology, Hospital for Sick Children, Great Ormond Street, London WCIN 3JH.

Received 13 June 1983 